\title{
From the Editors
}

As announced in issues 111.1 and 111.2, Hans Adler has retired as co-editor. We thank him for his many years of service to the journal and we look forward to working with Book Review Editor Sabine Gross, authors, peer reviewers, and the Journals Division of the University of Wisconsin Press in the years to come.

—Hannah V. Eldridge and Sonja E. Klocke 